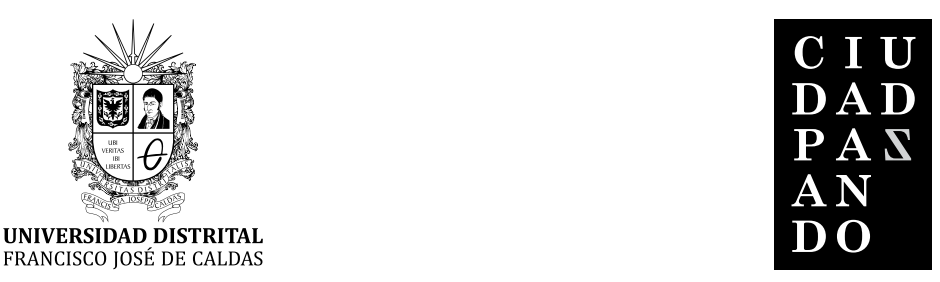

DOSSIER

Artículo de investigación científica

\title{
La Organización de Estados Americanos (OEA): una aproximación a su papel de verificación en el proceso de desmovilización paramilitar en Colombia $^{1}$
}

The Organization of American States (OAS): an approach to its role of verification in the paramilitary demobilization process in Colombia

A Organização dos Estados Americanos (OEA): aproximação do papel de verificação no processo de desmobilização paramilitar na Colombia

\section{Hugo Fernando Guerrero Sierra ${ }^{2}$}

\section{Paula Daniela Moncada Gaitán ${ }^{3}$}

\section{Angélica María Cabra Ramírez ${ }^{4}$}

Para citar este artículo: Guerrero, H., Moncada, P. y Cabra, A. (2017). La Organización de Estados Americanos (OEA): una aproximación a su papel de verificación en el proceso de desmovilización paramilitar en Colombia. Revista Ciudad Paz-ando, 10(2), 62-74.

doi: https://doi.org/10.14483/2422278X.12423

Fecha de recepción: 21 de agosto de 2017

Fecha de aprobación: 27 de octubre de 2017

\footnotetext{
1 Este escrito es un avance del proyecto de investigación "Postconflicto y agenda internacional: una lectura multidimensional", financiado por la Universidad de La Salle.

2 Doctor en Relaciones Internacionales, Unión Europea y Globalización, Universidad Complutense de Madrid. Docente de tiempo completo y director del Grupo Interdisciplinar de Investigación en Política y Relaciones Internacionales, Universidad de La Salle, Colombia. Correo electrónico: hfguerrero@unisalle.edu.co

3 Estudiante del programa de Negocios y Relaciones Internacionales, Universidad de La Salle, Colombia. Correo electrónico: pmoncada47@ unisalle.edu.co

4 Estudiante del programa de Negocios y Relaciones Internacionales, Universidad de La Salle, Colombia. Correo electrónico: acabra13@unisalle. edu.co
} 


\section{RESUMEN}

El propósito de este artículo es proporcionar un análisis cualitativo y crítico del papel de la Organización de los Estados Americanos (OEA) en el proceso de verificación de los acuerdos que condujeron a la desmovilización de grupos paramilitares en Colombia, específicamente durante los mandatos del expresidente Álvaro Uribe Vélez; en este sentido, el presente estudio ofrece un análisis de la historia de la OEA como gestor de conflictos y crisis democráticas en América Latina, para así abordar específicamente sus limitaciones en el contexto propuesto.

Palabras clave: Colombia, conflicto armado, desmovilización paramilitar, gestión de conflictos Organización de Estados Americanos, verificación.

\section{ABSTRACT}

The purpose of this article is to provide a qualitative and critical analysis of the role of the Organization of American States (OAS) in the verification process of the agreements that led to the demobilization of paramilitary groups in Colombia, specifically during the mandates of President Álvaro Uribe Vélez. In this sense, this study offers an analysis of the history of the OAS as a mediator of conflicts and democratic crises in Latin America, to identify its limitations in the proposed context.

Keywords: armed conflict, Colombia, conflict management, Organization of American States, paramilitary demobilization, verification.
O objetivo deste artigo é fornecer uma análise qualitativa e crítica do papel da Organização dos Estados Americanos (OEA) no processo de verificação dos acordos que levaram à desmobilização de grupos paramilitares na Colômbia, especificamente nos mandatos do presidente Álvaro Uribe Vélez. Nesse sentido, este estudo oferece uma análise da história da OEA como mediadora de conflitos e crises democráticas na América Latina, a fim de identificar suas limitações no contexto proposto.

Palavras-chave: Colombia, conflito armado, desmobilização paramilitar, gestão de conflitos, Organização dos Estados Americanos, verificação. 


\section{Introducción}

Si bien es cierto que en las últimas décadas el multilateralismo ha experimentado un importante avance y las Organizaciones Internacionales (OI) han ido ganando terreno como entes de deliberación y apoyo ante las diferentes problemáticas que afronta la comunidad internacional, su fuerte carácter intergubernamental se ha convertido en el principal obstáculo que se opone a su efectiva proyección como entes de decisión capaces, legítimos e independientes. Pero si las limitaciones de las OI en la contención y gestión de conflictos internacionales son un hecho probado, la gran eclosión de guerras intraestatales experimentada desde principios de los años noventa plantea un reto aún más complejo. El carácter asimétrico de este tipo de conflictos y las barreras impuestas por el principio casi absoluto de la soberanía estatal, se han constituido en dos inconvenientes adicionales frente a los que las OI no han logrado hallar una respuesta efectiva.

En el caso específico de la Organización de Estados Americanos (OEA), esta situación ha sido mucho más evidente, pues la incuestionable posición hegemónica de los Estados Unidos en el hemisferio desde el fin de la Segunda Guerra Mundial ha impedido que este organismo asuma de forma eficaz la gestión de los conflictos y crisis democráticas que han afectado a la región. A partir de este contexto, en el siguiente artículo se estudiará el cómo todas estas dinámicas determinaron la participación de la OEA en la gestión del conflicto colombiano, específicamente en el marco del acompañamiento al proceso de desmovilización de las Autodefensas Unidas de Colombia (AUC); en ese sentido, se hará un recorrido analítico por sus antecedentes como escenario de interlocución regional frente a las crisis, su nivel de independencia y, por último, los alcances de su involucramiento y la naturaleza de los programas que acompañaron el contexto de la polémica desmovilización paramilitar en Colombia.

\section{La Organización de los Estados Americanos (OEA) y sus antecedentes como instrumento de estabilización}

La Organización de Estados Americanos ha sido reconocida desde su nacimiento como el principal espacio de diálogo y cooperación intergubernamental del continente americano. Fue creada el 30 de abril de 1948 mediante la aprobación por parte de veintiún países de la Carta de la Organización de los Estados Americanos o Carta de Bogotá, ${ }^{5}$ acuñando como su principal objetivo la defensa de los intereses mutuos desde el respeto al principio de soberanía de cada uno de sus miembros. Actualmente, de los 35 países que han ratificado su adhesión a la organiza-

\footnotetext{
5 Véase el texto completo de la Carta de Bogotá en: www.oas.org/
} juridico/spanish/carta.html ción, 34 ejercen su participación de manera plena. ${ }^{6}$ En su proceso de evolución, junto con el aumento de sus miembros, la OEA también ha ido depurando sus objetivos en función de los retos que a lo largo de más de sesenta años ha venido enfrentando la región; en tal sentido se pueden identificar, entre otros:

el fortalecimiento de la paz y la seguridad, la consolidación de la democracia, el apoyo al desarrollo económico, social y cultural, la promoción de los derechos humanos y la lucha contra problemas compartidos como la pobreza, el terrorismo, las drogas ilícitas y la corrupción. (OEA, 2009a)

Sin embargo, más allá de los principios que nutren a cada uno de sus objetivos, la realidad muestra una OEA frecuentemente cuestionada por su incapacidad para dar cumplimiento a sus mandatos, al igual que por su falta de independencia ante el fuerte poder hegemónico que han ejercido históricamente los Estados Unidos en el hemisferio. Desde su creación, el propósito de la OEA de velar por el mantenimiento de la paz y la seguridad, en un marco de respeto al principio de no intervención, ha sido avasallado una y otra vez por su falta de eficacia y coherencia a la hora de concertar los mecanismos que garanticen tanto su autonomía como sus capacidades de reacción ante gran parte de las crisis experimentadas en el continente.

Por otra parte, la adopción casi paralela del Tratado Interamericano de Asistencia Recíproca (TIAR), ${ }^{7}$ que complementa el sistema de seguridad hemisférico, estableció la obligación de los Estados firmantes a reaccionar en contra de cualquier ataque del que sea objeto cualquiera de sus similares. Sin embargo, si se tiene en cuenta el

6 En la Octava Reunión de Consulta celebrada el 31enero de 1962 en Punta del Este, Uruguay, los países miembros decidieron suspender mediante la Resolución VI la participación de la República de Cuba por considerar "que la adhesión de cualquier miembro de la OEA al marxismo-leninismo es incompatible con el Sistema Interamericano y el alineamiento de tal Gobierno con el bloque comunista quebranta la unidad y la solidaridad del hemisferio" (OEA, 2003). El 3 de junio de 2009 los países miembros adoptaron la Resolución AG/RES 2438, mediante la cual dejaron sin efectos la Resolución VI de enero de 1962, invitando al Gobierno cubano a iniciar los diálogos con miras a la reactivación de su participación plena; sin embargo, dos años después, Cuba se ha negado a iniciar ese proceso.

7 El TIAR fue suscrito el 2 de septiembre de 1947 en la ciudad de Río de Janeiro. Actualmente el Tratado incorpora la participación de veintidós Estados. Su principal objetivo fue el de crear un espacio de seguridad continental sobre el supuesto de que "en caso de un ataque armado por cualquier Estado contra un Estado Americano, será considerado como un ataque contra todos los Estados Americanos, y en consecuencia, cada una de las Partes Contratantes se compromete a ayudar a hacer frente al ataque en ejercicio del derecho inmanente de legítima defensa individual o colectiva que reconoce el Artículo 51 de la Carta de las Naciones Unidas" (TIAR, art. 3). Disponible en: http://www.oas.org/juridico/spanish/tratados/b-29.html 
carácter omnipresente de los Estados Unidos en los asuntos continentales después de la Segunda Guerra Mundial, es evidente que más allá de su retórica solidaria, el TIAR abrió las puertas a que ante la subjetiva percepción de lo que la potencia dominante pudiera considerar como una amenaza o agresión, se crearan las condiciones para relativizar discrecionalmente del principio de no intervención establecido en la Carta de Bogotá.

Durante el periodo que comprendió la Guerra Fría, varios son los ejemplos a los que se pueden acudir para reforzar la validez de estas afirmaciones. La apelación recurrente a los principios de no intervención de la OEA y de mutua asistencia del TIAR, en función de los postulados anticomunistas de los Estados Unidos, llevó a que la aplicación del sistema de seguridad americano se convirtiera en una amplia sumatoria de contradicciones; por una parte, de la mano del principio de no intervención, la OEA se sustrajo de reaccionar ante numerosas situaciones que cuestionaban de forma evidente sus principios democráticos, tal fue el caso de las dictaduras anticomunistas que entre 1948 y 1990 asolaron casi la totalidad del continente, las cuales, en su mayoría, contaron con el manto protector de los Estados Unidos (Swift, 2003; Roitman, 2003). De otro lado, desechando el principio de no intervención y retomando el de mutua asistencia y conveniencia, la OEA se convirtió en ente legitimador del más crudo intervencionismo norteamericano, avalando, bien fuera de forma expresa o tácita, actuaciones tan reprochables como el apoyo al golpe de Estado de 1954 en contra de Jacobo Árbenz en Guatemala; el intento de invasión de Bahía Cochinos, Cuba, en 1961; la invasión a República Dominicana en 1965; la organización y financiación del golpe militar perpetrado por Augusto Pinochet en 1973 en Chile; la financiación y adiestramiento de la Contra nicaragüense a principios de los años ochenta; la invasión de la isla de Granada en 1983 y la invasión de Panamá en 1989.

Durante la década de los ochenta, el desgaste de la Guerra Fría y los constantes obstáculos impuestos por los Estados Unidos a la independencia de la organización, conllevaron a que la OEA empezara a redefinir su papel a riesgo de ir quedando excluida de los importantes procesos de pacificación y transformación democrática que empezaban a darse en el continente; el mejor ejemplo de este nuevo escenario fue la creación del Grupo de Contadora, ${ }^{8}$ el cual, al margen de la OEA y con la expresa oposición de los Estados Unidos, asumió en 1983 un importante papel mediador en los conflictos centroamericanos. Si bien, el grupo de Contadora no logró concretar la salida negociada a la crisis centroamericana, sí estableció unas bases sólidas para que entre 1986 y 1987, mediante la firma de los Acuerdos de Esquipulas, se diera el paso

8 Colombia, México, Panamá y Venezuela. decisivo hacia la solución de los conflictos armados de la región, esta vez con un mayor involucramiento de parte de la OEA, la cual se constituyó en agente verificador de la desmovilización y reinserción de la Contra nicaragüense. ${ }^{9}$ En el mismo sentido, el ocaso de las dictaduras militares durante la década de los ochenta, sumado al debilitamiento de la percepción del comunismo como fuente de amenaza regional después de la caída del Muro de Berlín, propiciaron que los Estados Unidos fueran permitiéndole adquirir a la OEA una mayor autonomía en sus actuaciones.

\section{La resolución 1080}

La consolidación en la década de los noventa del continente americano como una zona eminentemente democrática, salvo contadas excepciones como lo es el caso de Cuba, propició que los Estados Unidos asumieran con mayor tranquilidad la revitalización del diálogo multilateral al interior de la OEA; este nuevo escenario, caracterizado por un evidente optimismo democrático, llevó a que los países miembros comprendieran la necesidad de avanzar en la creación de mecanismos que dotaran a la Organización de las herramientas necesarias para reaccionar en aquellos casos en los que la democracia pudiera verse vulnerada. El primero de estos instrumentos al que haremos mención es la Resolución 1080 sobre Democracia Representativa (R-1080), adoptada por la asamblea general ${ }^{10}$ el 5 de junio de 1991 en la ciudad de Santiago de Chile. Esta resolución otorgó al secretario general de la organización el atributo de convocar a reuniones extraordinarias al Consejo Permanente,$^{11}$ con el fin de buscar alternativas ante hechos que menoscaben de forma abrupta e irregular el ejercicio libre y legítimo de los gobiernos elegidos democráticamente en cada uno de los Estados miembros (OEA, 1991a; Raymont, 2007). Dicha instancia, además de evaluar y proponer opciones de solución a este tipo de crisis, tiene la facultad de convocar extraordinariamente a reuniones ad hoc a los cancilleres de los países miembros o a la asamblea general en el caso que las soluciones planteadas no resulten suficientes (Bloomfield, 1994; Kunz, 2008). En la misma línea, con el fin de complementar el alcance de la Carta de la OEA y

9 La Comisión Internacional de Apoyo y Verificación "CIAV" de la OEA, se creó mediante acuerdo firmado por los presidentes centroamericanos el 7 de agosto de 1989 en la ciudad de Tela, Honduras. Desarrolló su misión entre 1990 y 1997, facilitando en este periodo el desarme y desmovilización de aproximadamente 22.500 combatientes, la repatriación de 18.000 nicaragüenses desde Honduras y Costa Rica, y la provisión de asistencia humanitaria a más de 120.000 personas (OEA, 2010).

10 La asamblea general es el máximo órgano decisorio de la OEA. Se reúne anualmente de manera ordinaria o de manera extraordinaria en circunstancias excepcionales.

11 El Consejo Permanente está compuesto por un representante de cada Estado miembro nombrado con categoría de embajador permanente. El consejo depende directamente de la asamblea general. 
de la R-1080 en situaciones de golpes de Estado, el 14 de diciembre de 1992 la asamblea general aprobó el Protocolo de Washington, el cual estableció los mecanismos para suspender el derecho de participación ante las diferentes instancias de la Organización de los Gobiernos de Facto (OEA, 1992).

Poco tiempo transcurrió desde la adopción de la R-1080 hasta el momento en que se aplicó por primera vez. A consecuencia del golpe de Estado perpetrado en Haití por el General Raúl Cedrás en contra de Jean-Bertrand Aristide, el 30 de septiembre de 1991, la OEA invocó la R-1080 para reaccionar de forma inmediata ante un acontecimiento que claramente ponía en peligro el libre ejercicio de un gobierno legítimamente constituido. La OEA puso en marcha cada uno de los mecanismos a su alcance: aplicó sanciones económicas como el establecimiento de un embargo comercial, desconoció el gobierno de facto y solo reconoció como interlocutores válidos a los representantes de Aristide y, por último, conformó una misión civil de apoyo a la democracia (OEA 1991b; 1991c; Ramírez, 1992). Sin embargo, a pesar del admirable compromiso democrático demostrado por la OEA, los mecanismos diplomáticos y civiles con que contaba la organización resultaron insuficientes para evitar la degradación de la crisis, razón por la cual se vio avocada a solicitar el apoyo a las Naciones Unidas, conformándose así en 1993, con el objetivo central de vigilar la situación de los derechos humanos, la primera misión civil conjunta ONU/OEA (MICIVIH; Zanotti, 2011; Granderson, 2000).

Lastimosamente, el ánimo democrático que inspiró el involucramiento de la OEA en Haití, no se reprodujo con la misma coherencia un año después cuando Alberto Fujimori desconoció el ordenamiento constitucional peruano y concentró todos los poderes en cabeza del Ejecutivo; en este caso, si bien se siguieron los procedimientos formales de condena al gobierno de facto, la organización poco a poco fue relativizando el carácter ilegítimo del autogolpe ante los supuestos compromisos de Fujimori por "recomponer" el orden democrático y el equilibrio de poderes (García-Sayán, 1999); sin embargo, como se había anunciado desde diferentes sectores, poco tiempo después quedó demostrado que medidas como la convocatoria de una asamblea constituyente no eran otra cosa que la instrumentalización en función de un interés particular de mecanismos aparentemente democráticos.

La tercera vez que se aplicó la R-1080 se dio en el marco de una situación comparable a la acontecida en el Perú. Luego de que el 23 de mayo de 1993 el presidente de Guatemala, Jorge Serrano Elías, disolviera los poderes legislativo y judicial, la OEA puso en marcha los mecanismos previstos para abordar la situación y conformó una misión encabezada por el propio secretario general, João Clemente Baena Soares, la cual se trasladó a dicho país con el fin de establecer los canales de diálogo que permitieran una pronta salida a la crisis (Herrera-Lasso, 1997); no obstante, ante la negativa del ejército de mantener su apoyo a Serrano, este se vio obligado a pocos días después, abriendo el camino al fin de la situación de anormalidad democrática y con ello, a las gestiones de la OEA.

La última ocasión en que se aplicó la R-1080 fue el 22 de abril de 1996 a consecuencia del intento de golpe de Estado del general Lino Oviedo al presidente Juan Carlos Wasmosy en Paraguay. En este caso, los mecanismos de la OEA fueron complementados de forma importante por Mercosur, la cual amenazó con excluir a Paraguay del acuerdo de integración. Esta ejemplar muestra de colaboración entre ambos organismos internacionales permitió que la normalidad constitucional retornara al Paraguay tan solo dos días después de desatada la crisis (Horwitz, 2010).

\section{La carta democrática interamericana}

La Carta Democrática Interamericana (CDI) es considerado como el instrumento más importante y consolidado con que cuenta la OEA para la defensa y preservación de la democracia en la región. Adoptada de manera unánime por la asamblea general el 11 de septiembre de 2001 en la ciudad de Lima, Perú, la CDI viene de alguna manera a sistematizar y complementar en un solo cuerpo las disposiciones que en materia de defensa de la democracia incorporan la Carta de la OEA, la R-1080 e instrumentos como el Protocolo de Washington (Marcano, 2005; Vasco, 2006). Así pues, la CDI puede ser considerada como una suerte de compendio que integra la evolución de la doctrina y la normatividad de la OEA respecto de la defensa de la democracia representativa como modelo de organización política imperante en América (Aguiar, 2006).

La CDI está integrada por 28 artículos agrupados a su vez en seis capítulos. El primero de ellos se dirige esencialmente a asumir el concepto de democracia representativa como inherente al sistema interamericano, considerándole como un "derecho de los pueblos de América", el cual debe ser "promovido y defendido por todos los gobiernos". Los capítulos segundo y tercero introducen de manera expresa la íntima e indisoluble relación entre el ejercicio de democracia, el efectivo disfrute de los derechos humanos y las libertades fundamentales, y el desarrollo económico y social de los pueblos, lo cual implica la apropiación de un concepto de democracia mucho más extenso que va más allá del simple ejercicio de los derechos políticos.

En el cuarto apartado se recogen los mecanismos de reacción previstos con anterioridad en la carta de la OEA, la R-1080 y el Protocolo de Washington, para casos en que se pongan en riesgo el orden constitucional y el legítimo ejercicio del poder en alguno de los Estados miembros, es decir, que se supera la idea de que las gestiones y sanciones de la OEA se vinculan de forma exclusiva a los golpes de Estado, abriendo el camino a una posible movilización de la Organización ante situaciones que, si 
bien no signifiquen una interrupción total del orden democrático, puedan considerarse como una amenaza grave para el normal desarrollo de este. El quinto capítulo establece el potencial papel de la OEA como observador de las garantías y coadyuvador de los Estados en el marco de los procesos electorales; sin embargo, se hace explícito que dichas funciones solo son posibles siempre y cuando medie una solicitud previa de los Estados interesados. Por último, el sexto capítulo aborda el papel de la OEA como promotor de la cultura democrática en la zona; para ello, establece la necesidad de cooperar con los Estados y las organizaciones de la sociedad civil con el fin de poner en marcha iniciativas dirigidas a "fortalecer la gobernabilidad, la institucionalidad política, la buena gestión pública y los valores democráticos". ${ }^{12}$

Después de su aprobación, la CDI fue invocada por primera vez luego del intento de golpe de Estado en contra del presidente Hugo Chávez, producido el 11 de abril de 2002 en Venezuela. Con motivo de estos hechos, la OEA reaccionó solicitando tanto a los manifestantes que apoyaban la intentona golpista como al mismo Gobierno, actuar con la máxima cordura y privilegiar las vías de negociación pacífica. Una vez Pedro Carmona juramentó como presidente de facto, haciendo efectivo así el golpe de Estado, la OEA condenó los hechos y conformó una misión encabezada por el secretario general de la organización, César Gaviria, la cual se dirigió a Caracas con el fin de evaluar los hechos y buscar un acercamiento entre la parte que pusiera fin a la situación de anormalidad constitucional. A pesar de que el 13 de abril Chávez pudo retomar el poder, la OEA comprobó que el ambiente de crispación era de tal magnitud que, de no adelantarse un proceso de negociación profundo entre el Gobierno y los grupos opositores, la reaparición de la violencia sería solo cuestión de tiempo, razón por la cual asumió, junto con el Centro Carter y el PNUD, el papel de mediadores de la crisis (Omaña, 2008; Ramis, 2010). Fruto de este esfuerzo, las partes acordaron abrir la vía a la realización de un referendo revocatorio. Con este acuerdo, la OEA declaró reinstaurada la normalidad democrática y concluyó su papel mediador, no sin antes ofrecer su acompañamiento como observador del proceso de convocatoria del referendo; finalmente, los comicios se llevaron a cabo el 15 de agosto de 2004, dejando como resultado un mayoritario apoyo a la continuidad de Chávez con el $59 \%$ de los votos a su favor (Dupret, 2004).

En los últimos años, la alusión más importante a la CDI se produjo a consecuencia del golpe de Estado perpetrado el 28 de junio de 2009 en contra del presidente de Honduras, Manuel Zelaya. A raíz de estos hechos, la OEA procedió a condenar la violación al ordenamiento

12 Véase el texto completo de la CDI en: http://www.educadem.oas. org/documentos/dem_spa.pdf constitucional hondureño y desconoció la legitimidad del gobierno de Roberto Micheletti, al tiempo que, por primera vez en ocho años de vigencia de la CDI, invocó el artículo 21 para suspender el derecho de participación en la organización a un Estado miembro ${ }^{13}$ (Duxbury, 2011; OEA, 2009b; 2009c). Sin embargo, a pesar del enfático pronunciamiento inicial de la OEA y de la suspensión del derecho de Honduras a participar en la organización, esta se mostró incapaz de promover el consenso necesario entre sus miembros que permitiera forzar el regreso de Zelaya al poder; ${ }^{14}$ por el contrario, ante la incapacidad de llegar a un acuerdo con el Gobierno de Micheletti y del fracaso de intentos de mediación como el adelantado por el presidente de Costa Rica, Óscar Arias, varios de los miembros de la OEA empezaron a mostrar su condescendencia con la situación y terminaron por avalar el resultado de fórmulas como la de las elecciones del 29 de noviembre de 2009 , donde sin la participación de Zelaya, resultó elegido como presidente Porfirio Lobo.

Con posterioridad a que Lobo se posesionara como nuevo presidente electo, la posición de la OEA frente a la situación hondureña fue debilitándose cada vez más. Lejos de mostrarse como una herramienta con capacidad de hacer frente de forma monolítica a sucesos que claramente revelan un flagrante ataque al principio de la democracia representativa, como lo fue el golpe de Estado del 28 de junio de 2009, la OEA dejó ver la profunda debilidad que subyace tras su naturaleza eminentemente intergubernamental. Aunque buena parte de los Estados miembros de la Organización, específicamente aquellos liderados por gobiernos que guardaban algún tipo de simpatía ideológica con Zelaya, ${ }^{15}$ lograron jalonar que la OEA mantuviera su decisión de desconocer la legitimidad del Gobierno de Lobo, tal posición en poco tiempo comenzó a hacerse insostenible ante el masivo reconocimiento que empezó a darse desde diferentes sectores de la comunidad internacional. ${ }^{16}$

Esta situación llevó a que, a finales de mayo de 2011, con la mediación de los gobiernos de Colombia y Venezuela, Porfirio Lobo y Manuel Zelaya se reunieran en la ciudad de Cartagena de Indias con el fin de llegar a un

13 CDI, artículo 21. "Cuando la Asamblea General, convocada a un período extraordinario de sesiones, constate que se ha producido la ruptura del orden democrático en un Estado Miembro y que las gestiones diplomáticas han sido infructuosas, conforme a la Carta de la OEA tomará la decisión de suspender a dicho Estado Miembro del ejercicio de su derecho de participación en la OEA con el voto afirmativo de los dos tercios de los Estados Miembros. La suspensión entrará en vigor de inmediato".

14 Manuel Zelaya fue expulsado por el movimiento golpista a Costa Rica. Posteriormente, desde el 27 de enero de 2010, permaneció en el exilio en la República Dominicana.

15 Argentina, Venezuela, Brasil, Ecuador, Bolivia y Nicaragua.

16 La ONU, el FMI, El Banco Mundial, los Estados Unidos, España, México, Chile, Colombia, Perú, todos los países centroamericanos a excepción de Nicaragua, entre muchos otros. 
acuerdo que permitiera el reingreso de Honduras al seno de la OEA. En dicho encuentro, Lobo asumió el compromiso de permitir la vuelta de Zelaya a Honduras sin que se le persiguiera política ni judicialmente, al mismo tiempo que prometió iniciar un proceso que conllevara a la celebración de una asamblea constituyente (Salinas, 2011). Finalmente, como consecuencia directa del acuerdo de Cartagena, la asamblea general de la OEA, reunida de forma extraordinaria el 1 de junio del mismo año en Washington, decidió por 32 votos a favor y uno en contra aprobar el retiro de la suspensión que recaía sobre el Estado hondureño desde hacía 23 meses $^{17}$ (El Mundo, 2011).

\section{La misión de apoyo al proceso de paz (MAPP-OEA)}

Ante la renuencia de la ONU de participar en el proceso de desmovilización de los grupos paramilitares, el Gobierno de Álvaro Uribe, en su afán por encontrar una alternativa que legitimara internacionalmente el resultado de los diálogos, acudió al expresidente de Colombia y secretario general de la OEA, César Gaviria, para que favoreciera el involucramiento de la organización regional. Fruto del acercamiento entre Uribe y Gaviria, el 23 de enero de 2004 se celebró entre el Gobierno colombiano y la OEA el convenio que permitió la creación de una misión cuya función sería esencialmente la de acompañar y verificar el cumplimiento de los acuerdos. ${ }^{18}$

Mediante la Resolución 859 (1397/04), aprobada por el Consejo Permanente de la Organización, reunido el 6 de febrero de 2004 en la ciudad de Washington, la OEA, aludiendo a los principios y valores contenidos en la Carta de Bogotá y en la Carta Democrática Interamericana, formalizó su acompañamiento al proceso de paz en Colombia $^{19}$ (OEA, 2004a). El mandato aprobado para el desempeño de la misión se enmarcó en el más absoluto respeto al proceso de negociación emprendido por el Gobierno y los grupos armados ilegales en proceso de desmovilización, lo cual significó un claro límite a la posibilidad de que la OEA pudiera entrar a valorar los acuerdos suscritos

17 Ecuador fue el único país en votar negativamente a la propuesta de dar por terminada la suspensión impuesta por la OEA a Honduras. Dicha posición fue asumida por el Gobierno ecuatoriano en razón a que, desde su punto de vista, el Gobierno de Porfirio Lobo no había promovido una investigación que estableciera la responsabilidad por los delitos cometidos por la administración de facto de Roberto Micheletti, al igual que la de los militares que apoyaron el golpe de Estado (Europa Press, 1 junio de 2011).

18 Véase el texto del "Convenio entre el Gobierno de la República de Colombia y la Secretaría General de la Organización de los Estados Americanos para el acompañamiento al proceso de paz en Colombia" en: http:// scm.oas.org/doc_public/SPANISH/HIST_04/CP12208S06.DOC

19 Aunque la Resolución 859 (1397/04) prefiere referirse a las funciones de la Misión como "un apoyo al proceso de paz en Colombia", resulta claro que la invitación hecha por el Gobierno colombiano a la OEA no tenía otra intención que la de involucrarle exclusivamente como agente legitimador del proceso de desmovilización paramilitar. por las partes; por ejemplo, en favor de los derechos de las víctimas. En tal sentido, la naturaleza eminentemente pasiva de las funciones de la misión quedaría restringida, de acuerdo con el convenio de cooperación suscrito, a los siguientes puntos:

- Verificar el cumplimiento de los acuerdos sobre el cese al fuego y hostilidades, de desmovilización y desarme, y de reinserción de los grupos armados ilegales a los que llegue el Gobierno con los grupos armados organizados al margen de la ley ${ }^{20}$.

- Proponer, monitorear y evaluar la implementación de medidas de confianza y seguridad entre el Gobierno y los grupos armados organizados al margen de la ley, con el fin de prevenir incidentes que puedan perturbar el normal desarrollo del proceso de cese de fuego y de hostilidades, desmovilización y desarme y reinserción.

- Proponer al Gobierno y a los grupos armados organizados al margen de la ley otras recomendaciones para facilitar el desarrollo del proceso de negociación, pero no podrá participar ni opinar sobre el mismo, a menos que específica y puntualmente, su colaboración sea solicitada de común acuerdo por ellas (OEA, 2004b).

Precisamente, el profundo carácter restrictivo del mandato establecido en el convenio firmado entre el Gobierno y la OEA para el desarrollo de la misión, provocó que desde varios sectores de la sociedad civil se plateara una férrea oposición a que el Consejo Permanente avalara la puesta en marcha de dicho instrumento; de hecho, organizaciones como Human Rights Watch le solicitaron directamente al Consejo Permanente que no ratificara el convenio de cooperación, pues desde su perspectiva, no se podía dar inicio a una labor de verificación cuando los mínimos criterios que permitieran investigar y el establecer las responsabilidades por los crímenes de lesa humanidad cometidos por el paramilitarismo no habían sido determinados (Human Rights Watch, 2004). En la misma línea de argumentos, HRW señaló las carencias del mandato pactado para el funcionamiento misión, ya que como lo establece el convenio, sus roles de asesoría y verificación quedaban limitados ante la restricción que se le impuso de emitir juicios jurídicos y políticos respecto a las decisiones tomadas por el Gobierno (Human Rights Watch, 2004).

Bajo estos supuestos, HRW no dudó en anticiparse a declarar que la forma en que se venía diseñando la participación de la OEA en torno al proceso con los paramilitares,

20 Los acuerdos e instrumentos jurídicos a verificar por la misión fueron básicamente los siguientes: El acuerdo de Santa Fe de Ralito, suscrito el 15 de julio de 2003 entre el Gobierno y las AUC como punto de inicio de las negociaciones; el Acuerdo de Fátima, firmado el 13 de mayo de 2004 entre las partes, con el objetivo de crear una “Zona de Ubicación” donde se desarrollarían las conversaciones; y, por último, la Ley 975 de 2005 o Ley de Justicia y Paz, la cual estableció el marco de desmovilización de las estructuras paramilitares. 
lejos de dar cuenta de los principios de CDI como instrumento para fortalecer el Estado de derecho y la democracia en la región, abría el camino para que fuera invocada en Colombia para todo lo contrario. En tanto, la ausencia de un debate serio al interior de la Organización en cuanto a los parámetros que debían determinar el alcance del mandato de la Misión, terminaría por conferir de manera precipitada legitimidad internacional a un proceso que bien podría resultar en la impunidad de hechos atroces y de barbarie (Human Rights Watch, 2004). Así pues, como consecuencia directa del gran número de señalamientos que se aunaron a los ya expresados por HRW, el Consejo Permanente decidió incluir en la Resolución 859 un parágrafo que le asignó a la Corte Interamericana de Derecho Humanos (CIDH) la función de asesorar a la misión, buscando así generar entre los críticos la seguridad de que su apoyo se daría en un marco de pleno respeto a las normas internacionales de los derechos humanos y del DIH (OEA. 2004a).

La MAPP/OEA se puso en marcha a inicios de 2004 con la apertura de dos oficinas, una principal en Bogotá D.C., y una subsede en Medellín. Durante sus primeros meses de presencia en país, y ante la falta de previsión de una fuente fija de recursos que garantizara su normal funcionamiento, sus labores iniciales se centraron en definir su estructura organizativa, establecer los recursos humanos y financieros necesarios para su ejercicio, explicar su mandato a los diferentes sectores de opinión que así lo requirieran y, por último, salir en busca las donaciones que habrían de viabilizar su existencia. ${ }^{21}$ Esta situación de incertidumbre financiera llevó a que ya, en su primer informe, la misión expresara su preocupación frente a la dificultad que para el desarrollo integral de su mandato suponía la falta de un respaldo económico estable (OEA, 2004c).

Durante esta primera etapa, la misión adelantó sus labores apoyada en recursos provistos por el Gobierno colombiano, aunque durante el segundo semestre del 2004 empezó a recibir el llamado de actores internacionales como la Unión Europea y los gobiernos de Suecia y Holanda, interesados en explorar mecanismos de apoyo. Asimismo, para finales del 2004, la misión había logrado aumentar su presencia territorial mediante la apertura de siete oficinas adicionales a las ya existentes, principalmente en zonas neurálgicas dentro del proceso de desmovilización $^{22}$ (OEA, 2004d). Otro elemento problemático señalado por la misión, directamente relacionado con su llegada a varias regiones del país, fueron las limitaciones que representaba la escasa disponibilidad de recursos humanos especializados. Para ese entonces, la misión

21 La Resolución 859 estableció expresamente que la misión debía financiarse a través de contribuciones voluntarias.

22 Valledupar, Cesar; Cúcuta, Norte de Santander; Villavicencio, Meta; Barrancabermeja, Santander; y Montería, Santafé de Ralito y Tierralta en Córdoba. estaba integrada por tan solo ocho expertos internacionales, seis nacionales y cinco empleados de apoyo, cuando desde su perspectiva, para que las oficinas pudieran cumplir adecuadamente con sus funciones, cada una de ellas debía contar con al menos dos expertos internacionales, tres nacionales y el personal de apoyo suficiente (OEA, 2004d).

No obstante, a pesar de las limitaciones que implicó durante los dos primeros años de la misión la reducida disponibilidad de recursos económicos, humanos y logísticos, desde el 2006 esta situación empezó a solventarse de forma importante. En los informes presentados durante el 2006 y 2007, la misión dio cuenta del importante apoyo de Holanda, la cual para el 2005 se había constituido en el principal donante del programa. Asimismo, se anunció el compromiso de apoyo, bien fuera con dinero, equipos o personal experto de gobiernos entre los que destacaron los de Suecia, Irlanda, Brasil, Chile, Guatemala, Argentina, Canadá, España, Noruega, Estados Unidos, Bahamas, Tailandia y Corea del Sur. De igual manera, gracias a las ayudas recibidas, hacia finales del 2007 la misión había logrado quintuplicar su número de colaboradores a 103 personas, contando con 34 expertos internacionales provenientes de dieciséis países diferentes, ${ }^{23}$ diecisiete expertos de origen colombiano, 43 funcionarios de apoyo y nueve promotores comunitarios (OEA, 2006a, 2007).

La estructura administrativa de la misión también ha variado con el paso de los años. Actualmente, la misión cuenta con trece oficinas regionales, ${ }^{24}$ las cuales se han ido creando o reubicando a lo largo y ancho del país de acuerdo con las exigencias que ha venido imponiendo la evolución del proceso de desmovilización. Del mismo modo, hoy es posible encontrar una clara delimitación de las áreas de trabajo en las que la misión ha venido enfocando el desarrollo de su mandato, parcelándolo en tres líneas principales de acción.

- Justicia y Paz: encargada de monitorear el desarrollo y aplicación de la Ley 975 de 2005, al igual que los mecanismos de protección y reparación de la victimas por parte del Estado.

- Desarme, Desmovilización y Reinserción (DDR): destinada a hacer seguimiento al proceso de reinserción a la vida civil de los exparamilitares y el cumplimiento de los compromisos adquiridos por los desmovilizados.

- Acompañamiento comunitario: identificar los alcances y retos de los procesos de fortalecimiento institucional, reconstrucción del tejido social y reparación

23 Argentina, Bolivia, Brasil, Canadá, Chile, Costa Rica, Ecuador, España, Guatemala, Italia, Lituania, México, Nicaragua, Perú, Suecia y Uruguay (OEA, 2007).

24 Bogotá, Medellín, Cali, Bucaramanga, Barranquilla, Valledupar, Pasto, Puerto Asís, Quibdó, Villavicencio, Montería, Urabá antioqueño y San Pablo (sur de Bolívar). 
colectiva en zonas que fueron foco de las actividades del paramilitarismo.

De otro lado, en relación con el apoyo económico y logístico internacional al trabajo de la misión, es perceptible que el ambiente de despolarización que ha supuesto la llegada a la presidencia de Colombia de Juan Manuel Santos en cuanto a la forma de valorar el conflicto armado desde el gobierno ${ }^{25}$, ha permitido que la comunidad internacional se sienta mucho más cómoda a la hora continuar brindando el soporte necesario para que la OEA prosiga con sus tareas de verificación. Este renovado interés de los donantes internacionales ha quedado de manifiesto luego de que el presidente Santos renovara por tres años más el mandato de la misión en enero de 2011, dando paso así a que países como España, Holanda, Suecia, Suiza, Alemania, Noruega, Argentina, Chile, Brasil, México, Estados Unidos, Canadá y Corea del Sur anunciaran su intención de continuar brindando su apoyo. Al mismo tiempo que otros países, como Francia y el Reino Unido, expresaran por primera vez su deseo de sumarse en adelante como nuevos auxiliadores del programa (OEA, 2011a, 2011b, 2011c).

\section{El proceso de verificación}

La verificación puede entenderse a grandes rasgos como la observancia sobre el terreno del cumplimiento de los compromisos adquiridos por las partes en los acuerdos de paz; por tanto la verificación debe asumirse como una etapa del postconflicto, esencialmente aquella que sirve de puente entre el cese de la violencia a que lleva la firma formal de los acuerdos y la construcción material y sostenible de la paz. A su vez, la mayor parte de los procesos de verificación suelen girar en torno al monitoreo y control de tres tareas: el desarme, la desmovilización y la reinserción de los combatientes a la vida civil (DDR).

\section{Desarme}

El desarme, entendido como la primera etapa en esta secuencia de actividades, es ese periodo en el que los verificadores enfocan todos sus esfuerzos en procurar que los grupos combatientes que no hacen parte de las fuerzas armadas legítimamente constituidas por el Estado cumplan con el compromiso de poner fin a las hostilidades y hagan entrega efectiva de todo el armamento que permanece en su posesión, a fin de que sea almacenado y destruido.

25 Con la Ley de Víctimas y Restitución de Tierras de 10 de junio de 2011, impulsada por el Gobierno de Juan Manuel Santos, se da un importante paso hacia el reconocimiento oficial de la existencia de un conflicto armado en el país; muy al contrario de la posición defendida por Álvaro Uribe durante sus ocho años de mandato, para quien el problema de la violencia en Colombia se reducía a una expresión puramente terrorista.
En el caso que atañe a este texto, la verificación del cese de hostilidades ${ }^{26}$ por parte de la misión chocó inmediatamente con un proceso en el que los grupos paramilitares no conformaban un cuerpo único, al igual que tampoco obedecían necesariamente a una estructura jerarquizada. Como lo señalan Koonings y Nordquist (2005), el hecho de que no todos los grupos paramilitares participaran en la negociación, a la vez que los que sí participaron se caracterizaran por poseer líneas de mando laxas y una ubicación dispersa, conllevó a que el papel verificador de la misión en sus inicios fuera sumamente difícil. La carencia de personal experto, el peligro que implicaba interactuar con grupos que no se hicieron parte del proceso y el miedo de las comunidades a denunciar hechos que podían constituir una violación al cese de las hostilidades, se constituyeron en los principales obstáculos que tuvo que afrontar la misión durante esta primera etapa.

Estas dificultades en el desarrollo de las labores de verificación del cese al fuego y el desarme provocaron que la misión emprendiera importantes esfuerzos encaminados a establecer redes de cooperación con autoridades de orden nacional y local, ONG y otros organismos internaciones desplegados sobre el terreno, todo ello con el fin de cruzar información que pudiera facilitar la comprobación de violaciones a los acuerdos. Como resultado de esta etapa, la misión, junto con organismos como Amnistía Internacional y la CIDH, pudieron corroborar que pese a la vigencia del cese de hostilidades, entre el 2003 y el 2006 fueron numerosas las violaciones a los derechos humanos atribuibles a grupos relacionados con el paramilitarismo, llegando a registrarse como consecuencia directa de estos hechos el asesinato o desaparición de más de 2242 personas (Colectivo de Abogados, 2006); asimismo, fruto de esta inocultable situación, el mismo Gobierno nacional terminó por reconocer públicamente el reiterado incumplimiento de los compromisos adquiridos por parte de las estructuras paramilitares inmersas en el proceso de desmovilización (Colectivo de Abogados, 2006).

Con respecto a la entrega de armamento, para agosto del 2006 la misión había registrado la entrega de 17 540 armas entre largas, cortas y de apoyo, ${ }^{27}$ provenientes

26 Hacia finales de noviembre y principios de diciembre de 2002, las más importantes estructuras paramilitares del país anunciaron de forma unilateral un cese de hostilidades permanente como fórmula para facilitar el proceso de diálogo con el gobierno de Álvaro Uribe. Entre estos grupos, integrados en las Autodefensas Unidas de Colombia, se encontraban el Bloque Central Bolívar, las Autodefensas Campesinas de Casanare y las Autodefensas Campesinas del Meta y Vichada. En principio solo quedó excluido de este anuncio el Bloque Metro, operativo en la zona del nordeste antioqueño, el cual fue combatido y reducido por los mismos grupos paramilitares a consecuencia de su oposición al proceso (Oficina del Alto comisionado para la Paz, 2006).

27 Dentro de las armas largas la misión incluye fusiles, escopetas y carabinas; en las cortas subametralladoras, pistolas y revólveres; en las de acompañamiento, ametralladoras, lanzagranadas, morteros y lanzacohetes. 
principalmente de desmovilizaciones colectivas (OEA, 2006b); sin embargo, la labor de la misión en este aspecto fue calificada desde muchos sectores como superficial, pues más allá de registrar el número de armas e identificar su tipo, no logró hacer un registro minucioso de su procedencia y vinculación directa con cada uno de los potenciales desmovilizados. Del mismo modo, llama la atención que el número de armas entregadas no alcanzó a llegar ni a la mitad del número de personas desmovilizadas, lo que sin dudas es una clara muestra de dos posibles escenarios: por un lado, que buscando beneficios se hayan acogido al proceso personas que en realidad no hacían parte de las estructuras paramilitares; por otro, que buena parte de los arsenales no hayan sido entregados.

Al mismo tiempo, otros aspectos que generaron bastantes dudas frente a la trasparencia del proceso de desarme lo constituyeron el mal estado o lo inservible de gran parte de las armas entregadas, a la vez que muchas de ellas no fueran armas destinadas a operaciones de combate, como lo fueron escopetas, pistolas y revólveres (Colectivo de Abogados, 2006). Finalmente, en un emotivo acto presidido por el presidente Uribe, en el que fue acompañado por el secretario general de la OEA y por varios familiares de las víctimas, el 14 de diciembre de 2007, en una siderúrgica ubicada en la ciudad de Sogamoso, Boyacá, se procedió a la destrucción mediante fundición de 18051 armas de fuego ${ }^{28}$ (Semana, 14 de diciembre de 2007).

\section{Desmovilización}

Por su parte, el papel de la misión en la verificación de la desmovilización, entendida esta de manera general como la desarticulación voluntaria y definitiva de las estructuras militares de los grupos armados ilegales, fue tanto o más complejo que el emprendido en torno al proceso de desarme. Para empezar, es importante anotar que la desmovilización paramilitar se llevó a cabo bajo dos modalidades: individual y colectiva. En el caso de la primera, la intención del Estado fue debilitar la estructura del paramilitarismo (al igual que ha ocurrido con la guerrilla) mediante el ofrecimiento de beneficios de orden jurídico y asistencial para motivar entre los combatientes su deserción. Por tanto, las desmovilizaciones individuales no pueden considerarse como propias del proceso de paz, sino por el contrario, estaban ligadas a aquellos escenarios donde el Estado continuaba manteniendo una confrontación con sectores del paramilitarismo que no habían hecho efectiva su desmovilización en el marco de los acuerdos. Es decir que podían considerarse como la consecuencia directa de la aplicación de otra de las estrategias de guerra emprendidas por el Estado.

28 Junto con la destrucción de las armas de fuego, fueron inutilizadas 13117 granadas y 2716401 de unidades de munición (Oficina del Alto Comisionado para la Paz, 2007).
Como resultado del programa de deserción adelantado por el Gobierno, según informaciones aportadas el Ministerio de Defensa se estima que, entre el 7 de agosto de 2004, fecha de inicio del Gobierno Uribe, y abril de 2006, se registraron un total de 3170 desmovilizaciones individuales de paramilitares; sin embargo, en lo que resulta ser una clara inconsistencia y una buena muestra de descoordinación entre los entes públicos vinculados al desarrollo del proceso, organismos como el Fiscalía General de la Nación, exhibieron cifras muy diferentes, registrando en el mismo tiempo un total 3590 casos, es decir más de un $15 \%$ que lo sostenido por el Ministerio en sus informes (Colectivo de Abogados, 2006). Por su parte, la Fundación Ideas para la Paz (2010), experta en el monitoreo del conflicto colombiano, registró una cifra de 3682 desmovilizaciones individuales.

De otro lado, las desmovilizaciones colectivas son en la mayoría de los casos la consecuencia directa de los acuerdos alcanzados por las partes en el marco de un proceso de paz. Es así como, a diferencia de las efectuadas individualmente, las desmovilizaciones colectivas no pueden considerarse como el resultado de una estrategia de debilitamiento de parte del Estado en contra de un actor hostil, sino como el fruto de un diálogo pacificador entre actores que se consideran mutuamente como interlocutores válidos. Debido al carácter descentralizado del fenómeno paramilitar en Colombia, el proceso de desmovilización colectiva no se adelantó de manera unificada sino de modo fraccionado, es decir, por bloques y en diferentes tiempos y lugares; este proceso, que se desarrolló por algo más de dos años y medio, se inició el 25 de noviembre de 2003 con la desmovilización de 868 paramilitares pertenecientes al Bloque Cacique Nutibara. Esta primera desmovilización fue seguida por otras 38 desmovilizaciones colectivas de bloques y frentes que culminaron el 15 de agosto de 2006, dando como resultado la desmovilización total de 31671 personas, las cuales, sumadas a las 3682 desmovilizaciones individuales registradas por la Fundación Ideas para la Paz terminaron por arrojar un resultado global de 35353 paramilitares desmovilizados (Fundación Ideas para la Paz, 2010).

Entre los principales problemas que se originaron en el proceso de verificación de las desmovilizaciones, se tiene el gran desfase entre los estimados preliminares de paramilitares activos y el resultado final del número de desmovilizados. En el 2003, justo antes de iniciado el proceso de desmovilización, el Ministerio de Defensa calculó en 13514 el número de personas vinculadas a estos grupos armados ilegales, los cuales, al ser contrastados con la cifra total de desmovilizaciones obtenida hasta agosto de 2006, presenta un desbalance de más 20000 personas. Esta espectacular desproporción fue justificada por el Gobierno nacional supuestamente en razón a que, junto con los combatientes, también se había acogido al proceso personal civil que hacía parte de redes de apoyo 
y colaboración (Comisión Nacional de Reparación y Reconciliación. 2010); sin embargo, por más de que esta premisa pudiera llegar a considerarse como cierta, resulta claro que los actores verificadores terminaron por avalar una desmovilización contraria al principio de distinción que establece el DIH, pues como bien los señala la Comisión Nacional de Reparación y Reconciliación (Comisión Nacional de Reparación y Reconciliación, 2010):

Se aceptó dentro de la categoría de combatiente desmovilizado a personas de la población civil que han actuado en el marco de las relaciones sociales cotidianas y de forma que se veían precisadas a interactuar en determinadas circunstancias con actores armados irregulares presentes en su territorio, sin que por ello perdieran su carácter civil y la inmunidad de protección que conlleva.

En tal sentido, sumado a la falta de rigor de los verificadores al momento de cumplir de manera estricta con sus funciones en esta etapa del proceso, el aumento en casi un $300 \%$ en el número de desmovilizados previstos inicialmente pone de relieve tres escenarios:

- El absoluto desconocimiento del país, específicamente de las autoridades, frente a la verdadera dimensión del fenómeno paramilitar previo al inicio de la implementación de los acuerdos.

- La incapacidad de Gobierno y verificadores a la hora de controlar la participación de personas ajenas al proceso cuyo único fin era el de hacerse participes de los beneficios jurídicos y económicos previstos para los combatientes.

- Como ha sido denunciado desde diferentes sectores, que el Gobierno y los grupos paramilitares hayan estimulado falsas desmovilizaciones con el fin de inflar las cifras, buscando de esta manera presentar como exitoso un proceso de paz fuertemente cuestionado desde sus inicios (El Espectador, 2011; Semana, 2011).

\section{Reinserción}

La reinserción es la última etapa en el proceso de DDR y a su vez la más compleja. Está diseñada con el objetivo principal de reinsertar a los combatientes a la vida civil, todo ello mediante la puesta en marcha de mecanismos que les garantice desarrollar en condiciones dignas un nuevo proyecto de vida dentro del respeto a la institucionalidad y el Estado de derecho. Lastimosamente este proceso, que sin duda es el más largo y el que requiere mayor esfuerzo de parte del Estado, la comunidad internacional, los actores sociales y el reinsertado, suele ser al que menos atención se le presta en razón no solo a su complejidad, sino a que resulta mucho menos mediático para los actores políticos y los donantes que el de desarme y desmovilización.
De manera general, los gobiernos y la comunidad internacional tienden a conformarse con "vender" ante la opinión pública la consecución de la paz (negativa) que deviene del desarme y la desmovilización, pero en la mayoría de las ocasiones el entusiasmo y los apoyos que caracterizan el desarrollo de estas dos primeras etapas no logra transmitirse con la misma intensidad al proceso de reinserción; es así que la falta de compromiso de los actores llamados a liderar la reinserción como medio para la construcción de un modelo de paz positiva, termina por convertirse en la principal causa de frustración de los excombatientes, facilitando en el mediano plazo que esta sensación de abandono se traduzca fácilmente en el camino hacia el rebrote de esquemas de violencia teóricamente superados.

La reinserción de los paramilitares en Colombia puede considerarse un caso paradigmático de cómo no debe adelantarse un proceso de estas características. El proceso de reinserción nació condenado al fracaso desde el mismo momento en que las autoridades fueron incapaces de prever el volumen total de desmovilizados; las más de 20000 personas de más que se acogieron al proceso provocaron que en términos económicos y logísticos el modelo de reinserción planteado se tornara en absolutamente insostenible, impidiendo el cumplimiento mínimo de las expectativas de acoplamiento socioeconómico de los desmovilizados. Así pues, la promesa del Gobierno a los desmovilizados de garantizar un regreso a la vida civil con plenos derechos no tardó mucho en comenzar a diluirse. Este incumplimiento de los compromisos adquiridos por el Gobierno generó que aquellos que se acogieron al proceso se fueran convirtiendo en objeto fácil de estructuras paramilitares que no llegaron a desmovilizarse, los cuales les ofrecían la oportunidad de volver al campo y retomar el camino de la violencia como forma de supervivencia en contra de un escenario que les condenaba a un espiral de desempleo y pobreza en las ciudades (Mejía, 2008).

La ausencia de programas de integración productiva o la falta de pertinencia de los puestos en marcha provocaron que en poco tiempo el descontento de los desmovilizados empezara a manifestarse. Al principio este fenómeno empezó a ponerse de relieve con movilizaciones de protesta pacífica, luego con expresiones de reivindicación más violentas, hasta finalizar con procesos de reorganización y rearme de estructuras criminales que buscaban retomar las actividades económicas y los espacios de influencia territorial que habían permanecido bajo el control paramilitar (Mejía, 2008; Gómez, 2008). Fruto de que las desmovilizaciones no garantizaron el desmonte total del paramilitarismo y de que los compromisos con los reinsertados no se cumplieron, entidades como Indepaz registraron desde el 2006 una importante proliferación de grupos que entraron en disputa por el control territorios de influencia; de esta manera, se estima que en el 2010 existían más de 6000 individuos vinculados 
a grupos "neoparamilitares", los cuales hacían presencia en aproximadamente 300 municipios, mayoritariamente en zonas consideradas como antiguos bastiones paramilitares (Indepaz, 2011).

Del mismo modo se ha hecho evidente que la forma de actuar de los "neoparamilitares" o "nuevas bandas criminales (BACRIM)", como se les llama engañosamente desde los sectores oficiales, en muy poco se diferencian de los mecanismos utilizados por sus predecesores, haciendo del narcotráfico, la apropiación de tierras por medio del desplazamiento forzado y las violaciones sistemáticas a los derechos humanos las piedras angulares de su renovado poder ${ }^{29}$ (Vásquez, 2010; Arias y Romero, 2010). En tal sentido, lo que el Gobierno opta por llamar en la actualidad como BACRIM solo puede considerarse como la máscara bajo la que se oculta la metamorfosis del paramilitarismo y, por tanto, el fracaso de un proceso de reinserción que fue avalado apaciblemente por un actor verificador débil y manipulable, sin capacidad de oposición y denuncia.

\section{Referencias}

Aguiar, A. (2006). Código de Derecho Internacional. Caracas: Universidad Católica Andrés Bello.

Arias, A. y Romero, M. (2010). Sobre paramilitares, neoparamilitares y afines: crecen sus acciones, ¿qué dice el Gobierno? Revista Arcanos, 15, 34-45.

Colectivo de Abogados José Alvear Restrepo. (2006). Balance del proceso de desmovilización de los paramilitares en Colombia. En Corte a la impunidad: Colombia en la mira de la Corte Penal Internacional.

Comisión Nacional de Reparación y Reconciliación. (2010). La reintegración: logros en medio de rearmes y dificultades no resueltas. Recuperado de http://www.cnrr.org.co/new/publicaciones/ DDR.pdf

Dupret, P. (Septiembre de 2004). Fiesta democrática en Venezuela. Le Monde Diplomatique. Recuperado de https://mondiplo.com/ fiesta-democratica-en-venezuela

Duxbury, A. (2011). The participation of States in International Organizations: the role of human rights and democracy. Nueva York: Cambridge University Press. https://doi.org/10.1017/CBO9780511921445

El Espectador. (5 de marzo de 2011). Denuncias de “El Alemán” sobre falsas desmovilizaciones generan primeras reacciones. El Espectador. Recuperado de http://www.elespectador.com/noticias/ judicial/denuncias-de-el-aleman-sobre-falsas-desmovilizaciones-g-articulo-255042

El Mundo. (1 de junio de 2011). La OEA readmite a Honduras con la única oposición de Ecuador. El Mundo. Recuperado de http:// www.elmundo.es/america/2011/06/01/noticias/1306948847.

29 Se estima que en 2009 los ataques a la sociedad por parte de los grupos neoparamilitares ya doblaban en número a los atribuibles a la FARC. html

Salinas, C. (23 de mayo de 2011). Zelaya podrá regresar a Honduras. El Pais. Recuperado de https://elpais.com/internacional/2011/05/23/actualidad/1306101612_850215.html

Fundación Ideas para la Paz (FIP). (2010). Estadísticas sobre reinserción en Colombia. FIP.

García-Sayán, D. (1999). Vidas paralelas: Región Andina, desafíos y respuestas. Bogotá D.C: Ediciones Tercer Mundo.

Gómez, F. (2008). Justicia, verdad y reparación en el proceso de desmovilización en Colombia. En F. Gómez (Dir.), Colombia en su laberinto. Una mirada al conflicto. Madrid: Libros de la Catarata.

Granderson, C. (2000). Institutionalizing peace: the Haiti experience. En A. Henkin, (Ed.). Honoring Human Rights. La Haya: Kluwer Law International.

Herrera-Lasso, L. (1997). México en el ámbito de la seguridad hemisférica. En S. Aguayo, y J. Bailey (Coords.). Las seguridades de México y Estados Unidos en un momento de transición. Ciudad de México: Siglo XXI Editores.

Horwitz, B. (2010). The transformation of the Organization of American States: a multilateral framework for regional governance. Nueva York: Anthem Press.

Human Rights Watch. (2004). Carta a los Ministros de RR.EE. de los Estados Miembros de la OEA. Washington. Recuperado de http:// colombia.indymedia.org/news/2004/02/9619.php

González, C. (2010). Vinforme sobre narcoparamilitares en 2010: el avance del narcoparamilitarismo. Bogotá D.C: Indepaz.

Koonings, K. y Nordquist, K. (2005). Proceso de paz, cese al fuego, desarme, desmovilización y reintegración $-C D D R-$ paramilitar y (apoyo internacional a la) Misión de Apoyo al Proceso de Paz de la OEA -MAPP/OEA- en Colombia. Bogotá D.C.: Embajada de Suecia en Colombia-El Malpensante.

Marcano, L. (2004). Fundamentos de Derecho Internacional Público: introducción al estudio de la historia de las instituciones de derecho internacional público y su impacto en las relaciones internacionales. Caracas: Libros del Nacional.

Mejía, O. (2008). Paramilitarismo, desmovilización y reinserción: la Ley de Justicia y Paz y sus implicaciones en la cultura politica, la ciudadanía y la democracia en Colombia. Bogotá: Universidad Nacional de Colombia.

OEA. (1948). Carta de la Organización de los Estados Americanos. Bogotá D.C. Recuperado de www.oas.org/juridico/spanish/carta.html

OEA. (5 de junio de 1991a). Resolución 1080 sobre Democracia Representativa. Santiago de Chile. Recuperado de http://www.oas. org/juridico/spanish/res-1080.htm

OEA. (1991b). Resolución de Apoyo al Gobierno Democrático de Haití. MRE/RES. 1/91. Reunión Ad Hoc de Ministros de Relaciones Exteriores. Washington.

OEA. (1991c). Resolución de Apoyo a la Democracia en Haití. MRE/ RES. 2/91. Reunión Ad Hoc de Ministros de Relaciones Exteriores. Washington. Recuperado de http://www.oas.org/columbus/ 


\section{docs/HaitiMRERES291Spa.pdf}

OEA. (1992). Protocolo de Washington. 14 de diciembre. Washington. Recuperado de http://www.oas.org/dil/esp/tratados_A-56_ Protocolo_de_Washington.htm

OEA. (2003). La situación de Cuba en la OEA y la protección de los derechos humanos. CP/CG-1527/03. Washington: OEA. Recuperado de www.oas.org/columbus/docs/cp11248s04.doc

OEA. (2004a). Apoyo al Proceso de Paz en Colombia. CP/RES. 859 (1397/04). Recuperado de http://www.oas.org/consejo/sp/actas/acta1397.pdf

OEA. (2004b). Convenio entre el Gobierno de la República de Colombia y la Secretaría General de la Organización de los Estados Americanos para el acompañamiento al proceso de paz en Colombia. Bogotá D.C. Recuperado de http://scm.oas.org/doc_public/ SPANISH/HIST_04/CP12208S06.DOC

OEA. (2004c). Primer informe trimestral del Secretario General al Consejo Permanente sobre la Misión de Apoyo al Proceso de Paz en Colombia (MAPP/OEA). Bogotá D.C. Recuperado de_http:// www.acnur.org/t3/fileadmin/scripts/doc.php?file=biblioteca/ $\mathrm{pdf} / 4512$

OEA. (2004d). Segundo informe trimestral del Secretario General al Consejo Permanente sobre la Misión de Apoyo al Proceso de Paz en Colombia (MAPP/OEA). Bogotá D.C.. Recuperado de http:// www.acnur.org/t3/fileadmin/scripts/doc.php?file=biblioteca / $\mathrm{pdf} / 4513$

OEA. (2006a). Sexto informe trimestral del Secretario General al Consejo Permanente sobre la Misión de Apoyo al Proceso de Paz en Colombia (MAPP/OEA). Bogotá D.C. Recuperado de http:// www.acnur.org/t3/fileadmin/scripts/doc.php?file=biblioteca/ $\operatorname{pdf} / 4517$

OEA. (2006b). Séptimo informe trimestral del Secretario General al Consejo Permanente sobre la Misión de Apoyo al Proceso de Paz en Colombia (MAPP/OEA). Bogotá D.C. Recuperado de http:// www.acnur.org/t3/fileadmin/scripts/doc.php?file=biblioteca/ $\mathrm{pdf} / 4518$

OEA. (2007). Octavo informe trimestral del Secretario General al Consejo Permanente sobre la Misión de Apoyo al Proceso de Paz en Colombia (MAPP/OEA). Bogotá D.C. Recuperado de http:// www.acnur.org/t3/fileadmin/scripts/doc.php?file=biblioteca/ $\mathrm{pdf} / 4851$

OEA. (2009a). Democratización del conocimiento para la creación de una cultura de paz. Montevideo: Fondo de paz OEA.

OEA. (2009b). Situación actual de Honduras. CP/RES. No. 153 (1700/09). Recuperado de http://www.oas.org/consejo/sp/resoluciones/res953.asp

OEA. (2009c). Suspensión del derecho de Honduras de participar en la OEA. AG/RES. 2 (XXXVII-E/09). Washington. Recuperado de http://chileabroad.gov.cl/blog/noticias/2009/07/09/oeahonduras/

OEA. (2010). La Organización de los Estados Americanos: Paz, Democracia y Resolución de Conflictos. Washington: Fondo de paz OEA.
OEA. (11 de febrero de 2011a). Se renueva el mandato de la MAPP/ OEA en Colombia. Noticias MAPP/OEA. Bogotá D.C. Recuperado de http://www.mapp-oea.net/

OEA. (9 de mayo de 2011b). Jefe de Misión recibe el apoyo de los países europeos al trabajo de la MAPP/OEA por la paz de Colombia en su gira por el Viejo Continente. Noticias MAPP/OEA. Bogotá. D.C Recuperado de http://www.mapp-oea.net/

OEA. (20 de mayo de 2011c). Jefe de Misión presenta a los países donantes y amigos los avances en justicia transicional y tierras. Noticias MAPP/OEA. Bogotá D.C. Recuperado de http://www. mapp-oea.net/

Oficina del Alto Comisionado para la Paz. (2006). Proceso de paz con las autodefensas. Bogotá D.C: Indepaz.

Oficina de Alto Comisionado para la Paz. (2007). Inspección, empadronamiento, traslado y destrucción del material de guerra entregado por las autodefensas. Recuperado de http://www.altocomisionadoparalapaz.gov.co/noticias/2007/enero/documentos/ Informe_Armas.pdf

Omaña, R. (2008). La OEA en Venezuela: entre la democracia y el golpe de Estado. Quito: Universidad Andina Simón Bolívar.

Ramis, N. (2010). La OEA y la promoción de la democracia en la Américas: un objetivo en construcción. Working Papers. Barcelona: Institut Català Internacional per la Pau.

Ramírez, J. (1992). La OEA, la democracia y Haití. La nueva agenda de la organización regional. En: Colombia Internacional. 20, 3-8.

Roitman, M. (2003). Las razones de la democracia en América Latina. Ciudad de México: Siglo XXI Editores.

Semana. (14 de diciembre de 2007). Armas de los desmovilizados se fundieron como símbolo de reconciliación. Semana. Bogotá D.C. Recuperado de http://www.semana.com/on-line/articulo/armas-desmovilizados-fundieron-como-simbolo-reconciliacion/90047-3

Semana. (16 de marzo de 2011). Faltó trasparencia sobre quiénes eran los que se desmovilizaban. Semana. Bogotá D.C. Recuperado de http://www.semana.com/nacion/articulo/falto-transparencia-sobre-quienes-eran-desmovilizaban/236848-3

Swift, J. (2003). Atlas histórico de la Guerra Fría. Madrid: Ediciones Akal.

Vasco, M. (2006). Atalaya diplomático. Quito: Ediciones Abya-Yala.

Vásquez, T. (2010). La seguridad democrática de Uribe (2002-2010). Cien Días. 70.

Zanotti, L. (2011). Governing disorder: UN peace operations, international security, and democratization in the post-Cold war era. Pensilvania: Pennsylvania University Press. 